\title{
Experiential Learning In An Organizational Leadership Program
}

\author{
Joann Bangs, St. Catherine University, USA
}

\begin{abstract}
This paper is a case study of an experiential learning process in a research methods course. All students work together to complete a research project pertaining to their graduate program.
\end{abstract}

Keywords: Experiential Learning

\section{INTRODUCTION}

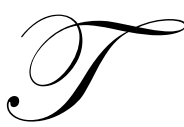

he idea of experiential learning is based on the simple idea so eloquently stated in the familiar quote from Confucius, "I hear and I forget. I see and I remember. I do and I understand." The best way to help students to truly understand concepts is to have them actually using the concepts in real world settings. To be more concrete, one definition of experiential learning comes from Hoover and Whitehead, 1975 (as quoted in Gentry, 1990, p. 10):

Experiential learning exists when a personally responsible participant cognitively, affectively, and behaviorally processes knowledge, skills, and/or attitudes in a learning situation characterized by a high level of active involvement.

There is a wealth of research on the topic of experiential learning theory. In Kolb and Kolb (2005), they note two comprehensive reviews of the topic performed by Hickcox and by Iliff. Both of these comprehensive studies show a remarkable level of support for the power of experiential learning.

\section{ACTIVE INVOLVEMENT}

The key to an experiential learning process is the active involvement of the students. They must be involved in shaping the process they will follow, guided not only by the concepts of the course, but also by their own personal knowledge and experiences they bring with them to the course. This paper discusses incorporating experiential learning in the Research and Analytical Skills for Decisions Making course in St. Catherine University's Master of Arts in Organizational Leadership (MAOL) program. The experiential learning is incorporated through a class research project spanning the length of the course. The students in the MAOL program must have at least two years of full-time work experience for admission so when students come to this course, they have a wealth of experience to draw upon. Although their experiences are not necessarily specifically related to doing research, they bring to the table experiences in working in organizations and in working collaboratively on projects. In addition, as the research project is related to the MAOL program, they also bring their own knowledge of the program into the experience.

In the past, the Research and Analytical Skills for Decision Making course had been taught using fairly traditional teaching methods - lectures, assigned readings, small group discussions, student presentations, etc. However the course content was well suited to incorporating experiential learning by designing a research project for the class. One of the strengths of the design of the research project for this course is that the project completes research to benefit the MAOL program. While the class is assigned a specific topic to research, the members of the class are empowered to make research decisions. The students are given a loose description of the topic and a client (the program director) to discuss with, but they select and implement research methodologies of their own choosing. This process helps to maximize the active involvement of the students in the project. 
It is not a unique idea to have students in a research methods class complete a research project. A unique aspect of this course is that the entire class works together on one project. This choice allows students to also practice other organizational leadership skills they have learned in their other classes in the program, such as project management and effective teamwork. It also means that the students' past experiences on project management and effective teamwork can be brought to the experiential learning process.

\section{CIRCULAR EXPERIENTIAL LEARNING PROCESS}

Research on learning shows that experiential learning can be a powerful tool, but it is more than simply having students work on a project. The Lewinian Model of Action Research and Laboratory Training (as reported in Kolb, 1984, p. 21) defines learning as a four-step, circular process. The steps include: 1) concrete experience, 2) observations and reflections, 3) formation of abstract concepts and generalizations, and 4) testing implications of concepts in new situations. This circular experiential learning process starts within the course, but continues as the students progress through the MAOL program and move onto completing their own research projects. ${ }^{1}$

To have a successful experiential learning process, it is crucial to pay attention to the four phases of experiential learning - Design, Conduct, Evaluation and Feedback (Wolfe and Byrne, 1975, as discussed in Gentry, 1990, p.11). Each of these four phases is discussed in relation to the experiential learning process designed for the Research an Analytical Skills for Decision Making course.

\section{DESIGN}

Design is the work done by the instructor before the course begins in order to set up the learning environment. The design for this experiential learning process is constrained by the calendar under which this course operates. In the MAOL program, courses meet eight times in a term, generally every other week. Students are expected to be doing a significant amount of work between class meetings and are given an assignment to complete prior to the first class meeting. A course management system is used to facilitate the work of the students outside of class meetings.

Prior to the first class meeting, students are given the research charge. The research charge gives students a broad idea of the topic to be researched and why it is of interest to the program. The program director selects a research topic that will be beneficial to the program and, together with the instructor, crafts the research charge. In a recent teaching of the course, the research charge was as follows:

Each year in its annual report, the MAOL program sets objectives to meet for the following year and reviews what progress was made on meeting objectives set the preceding year. In the area of Financial Effectiveness, the MAOL Program is committed to "providing a graduate education perceived by students as a 'good value' for their investment."

To gain a better understanding of the investment made by our students and the resources available to them, we need to know more about how MAOL graduate students finance their education. As researchers, your task is to conduct an analysis of the financial investment made by students pursuing graduate degrees and the resources available to them (financial aid in the form of loans, scholarships, research assistantships, tuition reimbursement, etc.) and make data-driven recommendations to the MAOL program.

The students are then instructed to begin the first step of any research project - a review of the literature. It is difficult to coordinate the work of a large number of students. To facilitate this process, students are assigned to small groups when they receive the research charge. It is recommended that students remain in the same small group throughout the term. In the MAOL program, we emphasize processes that facilitate well functioning groups, such as setting clear expectations for roles within the group. By allowing students to stay in the same small group throughout the term, rather than setting up groups as needed for each specific task, the time needed to be spent establishing these expectations is minimized. As there is a significant amount of work to be accomplished on the

\footnotetext{
${ }^{1}$ Students in the MAOL program are required to complete either an action research project or a thesis to earn their degree.
} 
research project, saving time in other areas is important.

Smaller groups (2-4 students) also tend to function better. These small groups allow for easier coordination of work outside of class meeting times and minimize the opportunity for free riders in the groups. To assist with holding students accountable, the grades for the class are based on some individual work, some work done by the small groups, and the final paper assembled by the class as a whole.

The first task for the small groups is to begin to work on the literature review. Each student must select and summarize at least three different scholarly sources related to the research charge. Through the use of discussion boards, each group discusses what they have learned from the sources they used. Each member of a small group must use sources that are different than the sources used by their group members. So, if Student A uses Source One, but finds when she goes to post on the discussion board, that Student B already made a post about Source One, Student A must find a different source. This rule has two main benefits. First, it increases the number of sources students will be familiar with prior to the first class meeting. Second, it gives them an incentive to begin posting their work on the discussion board sooner rather than later.

The students must come to the first class meeting with each member of the group ready to present a brief summary of what their group learned in their literature review process. Then, one member of each small group is randomly selected to present the findings of the group to the class. By the end of these presentations, the students have a much greater number of sources to draw from. Each small group is then assigned to together write one critical review of the sources used by all members of their small group. These critical reviews are posted on a class discussion board so all class members may utilize this information as the research project progresses. This process helps to reinforce that students are responsible not only for their individual work, but also for the work of the group.

The next task for the class is to decide on research questions for the project. Small groups are given time to discuss together in class. Then each small group shares their draft of research questions. Then an instructor facilitated discussion with all members of the class is utilized to get the class to agree on what research questions they will use to define the research project. Before the second class meeting, students are asked to brainstorm about what information they will need to effectively answer the selected research questions, and what research methodologies would best meet their data collection needs. In the second class meeting, the program director (the research client) comes to the class. The students present the research questions they have developed to ensure these questions will satisfy the needs of their client. They also engage in a discussion with their client about the research methodologies they are considering. At this time, the program director also provides the students with any applicable data she already has.

One of the jobs of the small groups is to facilitate the class' learning on the steps involved in the research process. Each small group has the job of making sure the class comes to a common understanding of the next step in the research process, and facilitates a process of determining how the class will proceed with the next step in the research process. After the discussion with the client is completed, one of the small groups works with the class to agree on what data they will collect, what methods will be used to collect the data, and what data each small group will be responsible for collecting.

The class then continues through the research process (developing research instruments, Institutional Review Board approval, data collection, data analysis, and writing the final report). At each of these steps, the work is done primarily within a small group. However, the groups make use of the course management system to stay in communication with each other. And as noted before, at each step, one small group is in charge of facilitating the next step.

\section{CONDUCT}

The second phase in the experiential learning process is conduct. That is, the instructor's process of monitoring the experience of the students and making any needed modifications to the design. As so much of the work done by the students on the research project happens outside of class time, it can be somewhat difficult to monitor the experiences of the students. To facilitate this process, at each class meeting, students are required to 
turn in a brief progress report of their individual contribution to the research project since the last class meeting. These progress reports along with discussion board postings on the course management system aid in monitoring the experience of the student. As the students in the MAOL program tend to be highly motivated, adjustments to the process are rarely required. However, progress reports do, at times, reveal that a student is not participating in the process at the same level as the rest of the class. When this happens, a discussion between the student and the instructor about changes required to be successful in the course is needed.

\section{EVALUATION}

The third phase in the experiential learning process (evaluation) is also aided by the student progress reports. The evaluation phase involves giving students opportunities to evaluate the learning they experienced during the process. In the student progress reports, students need to reflect on the work they have done. While this ongoing evaluation is important, it is crucial to allow the opportunity for an evaluation of the whole process at the end of the course. At the final class meeting of the course the class does a debrief of the research process they engaged in. The debrief provides an opportunity for students to give feedback on how to fine tune the course for the next time, but more importantly it allows the students to reflect on what they would have done differently in the research process with the benefit of 20/20 hindsight. This opportunity to think about what they could have done differently is crucial to the learning process. It is expected that mistakes will happen in experiential learning. After all, students are engaged in completing a major research project while they are learning about how to do that. Purposefully allowing students make mistakes in the research process can generate some of the strongest learning experiences, if the students have an opportunity to learn from the mistakes. The debrief provides this opportunity. In the debrief students are generally able to identify the mistakes that occurred in their research project and through class discussion, come up with better methods. However, the instructor should be prepared to bring up issues in the research project that need to be addressed during this debrief.

\section{FEEDBACK}

The fourth phase is feedback. The instructor needs to continuously engage in developing the positive outcomes in the process and removing negative experiences. As noted above, students are expected to make mistakes in the research process. However, the instructor must take care to ensure that the mistakes that are made do not result in such a strongly negative experience that the learning process is stalled. This feedback process begins in the first class meeting. The class engages in a discussion about the inevitability of mistakes being made as the class works together to complete the research project. These mistakes are framed as powerful learning experiences, not as failures. It is also important to give students a safety net. They need to know and be frequently reminded that they will receive enough guidance so as not fail at the research project. The grading criteria for the final project also contribute to the safety net. The criteria specify the expectation of the high quality research that can be completed by a group of Master's level students as they learn from their mistakes, rather than professional quality research.

One other aspect of the class project that aides in the feedback phase is that the client is the program director rather than an organization outside of the MAOL program. Having the research completed for someone that is an integral part of a program that stresses personal reflection and growth, helps to assure the students that they will not be judged too harshly for their growing pains as they grow and develop as researchers in this course.

\section{CONCLUSION}

The incorporation of an experiential learning component has allowed for an enormous amount of learning happening in a very short time frame with these students. However, not all students have fully benefitted from this process. Generally, these cases have been a result of a failure in the feedback phase. There have been students that were so worried about failure that they stopped learning in the course. One change that has been made to the course that has helped in this regard was to significantly reduce the class size. This change makes it much easier to monitor the students throughout the process and intervene as needed. It is not enough to simply put students into an experience where they can apply the concepts from the class. Rather critical attention must be paid to all four phases of the experiential learning process to succeed in having the students truly learn from the experience. 


\section{AUTHOR INFORMATION}

Joann Bangs has a B.S. in Economics from the University of Wisconsin-Madison, and both an M.A. and a Ph.D. in Economics from the University of Minnesota. She is currently an associate professor in the Department of Economics at the St. Catherine University. Her current research interests are active learning techniques. She developed a module on context-rich problems for Starting Point: Teaching Economics. E-mail: jmbangs@stkate.edu

\section{REFERENCES}

1. Gentry, J.W. (1990), "What is Experiential Learning.” In J.W. Gentry, ed. Guide to Business Gaming and Experiential Learning, East Brunswick, Nichols/GP Publishing.

2. Kolb, D.A., (1984), Experiential Learning: Experience as the Source of Learning and Development, Englewood Cliffs, NJ, Prentice Hall.

3. Kolb, D. A. and Kolb, A. Y. (2005), "Learning Styles and Learning Spaces: Enhancing Experiential Learning in Higher Education," Academy of Management Learning \& Education 4(2), pp. 193-212. 
NOTES 